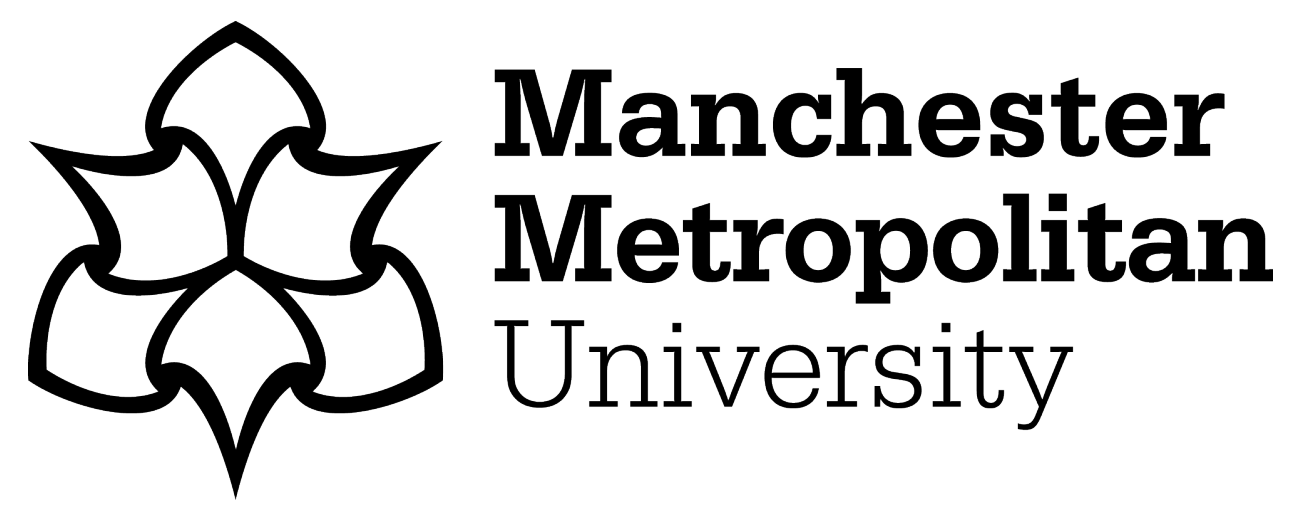

Edwards, Rodger, Lou, Eric, Bataw, Anas, Kamaruzzaman, Syahrul Nizam and Johnson, Chris (2019) Sustainability-Led Design: Feasibility of incorporating whole-life cycle energy assessment into BIM for refurbishment projects. Journal of Building Engineering, 24. ISSN 2352-7102

Downloaded from: https://e-space.mmu.ac.uk/622445/

Version: Accepted Version

Publisher: Elsevier

DOI: https://doi.org/10.1016/j.jobe.2019.01.027

Usage rights: Creative Commons: Attribution-Noncommercial-No Derivative Works 4.0

Please cite the published version 


\title{
Sustainability-Led Design: Feasibility of incorporating whole-life cycle energy assessment into BIM for refurbishment projects
}

\author{
Rodger E. Edwards, Eric Lou², Anas Bataw³, Syahrul Nizam Kamaruzzaman, \\ Christopher Johnson ${ }^{2}$
}

\footnotetext{
${ }^{1}$ School of Mechanical, Aerospace and Civil Engineering, University of Manchester, Manchester M13 9PL, United Kingdom.

2 School of Engineering, Manchester Metropolitan University, Manchester M15 6BH, United Kingdom.

${ }^{3}$ KEF Holdings, Dubai International Financial Center (DIFC), Dubai, United Arad Emirates.

4 The Centre for Building, Construction \& Tropical Architecture (BuCTA), Faculty of Built Environment, University of Malaya, 50603 Kuala Lumpur, Malaysia
}

\begin{abstract}
Growing climate change challenges and increasingly strict sustainability standards have led to a significant growth in the need for building refurbishment projects which are essentially focused on retrofitting in order to make them low carbon, energy efficient and environmentally friendly. The Waste and Resources Action Programme (WRAP) suggested that Building Information Modelling (BIM) should be used to achieve sustainability requirements during refurbishment projects as a correspondence to the National Audit Office (NAO) sustainability report. BIM is now widely advocated as the preferred tool for the management and co-ordination of design and construction data using object- oriented principles. The successful integration of environmental assessment into BIM for the whole of the construction lifecycle has not yet been achieved. The potential for using BIM in refurbishment projects specifically for achieving and managing sustainability requirements has not been yet critically reviewed or put into practice. This paper focuses on the use of BIM sustainability design tools in refurbishment projects, to achieve energy efficient buildings and achieve sustainability criteria for refurbishing non-domestic buildings. A critical lens is cast on the current literature in the domains of sustainable designs and the associated implications of the sustainability decision-support tools in BIM. The research also reviews the practicality of the existing sustainability decisionsupport tools that are currently used to assist with achieving environmental scheme certifications such as BREEAM and LEED for refurbishment projects.
\end{abstract}

Keywords: Sustainability-Led Design; BIM; Refurbishment; Energy 


\section{Introduction}

World wide, the buildings sector is responsible for significant resource consumption during construction, operation and demolition. There is great interest in achieving significant reductions in the quantities consumed as part of an overall move to greater sustainability: for example, energy has been the subject of particular interest because of its association with carbon dioxide $\left(\mathrm{CO}_{2}\right)$ emissions, which are central to climate change mitigation. Several environmental impact assessment tools, for example BREEAM and LEED, are now established and used within the design process (Kamaruzzaman et al., 2016; Meex et al., 2018). However, the promulgation of good practice is easier to achieve in the context of new construction. Tools for use during the planning of refurbishment are by comparison not as developed.

A further problem with refurbishment is that its success is heavily dependent upon having access to an appropriate amount of information which facilitates reliable characterising of the existing building, for example in terms of dimensions and materials of construction. For a number of reasons, drawings can be lost or damaged. What was designed is quite often not what was actually built and such changes are very often undocumented. Therefore, it may be necessary to recharacterise the existing building. Modern surveying method of laser scanning offers a fast and accurate means of capture building dimensions, whilst some technologies such as hyperspectral imaging show promise in the identification of materials present in an existing building.

The construction industry is in the early stages of a major technological advance in the shape of Building Information Modelling (BIM), which seeks to integrate all flows of information associated with a construction project and improve their accessibility by all project stakeholders (Sacks et al., 2018). Sustainability information and building recharacterisation data would be logical and valuable additions to the data available via BIM (Cavalliere et al., 2018). This paper surveys the existing state of knowledge with respect to environmental assessment in refurbishment projects and its integration into BIM.

\section{Research Methodology}

The sources that were searched for purposes of the literature review were firstly and most importantly the Library Catalogue of the University of Manchester and secondly the Internet via the Google search engine. The former is a portal to a digital collection 
of relevant information sources, for example the subscription journals available from all leading international publishers, e-books and reports. Sustainability and BIM are two topics whose main development has very much taken place in the digital age. The considerable paper-based holdings of the University of Manchester contain little of currency with respect to the subject matter of this paper. Google provides access to open access journals, government reports and legislation related documents, plus a miscellany of free to access material from the across the international arena. It is acknowledged that alternative search engines could have been used.

The review started with sustainability issues and focuses very quickly on those relevant in the built environment context and to refurbishment in particular. Key search terms in this regard were sustainability, construction, refurbishment. The review then moved on to take a more detailed look at whole-life cycle energy, which had very quickly been identified as the key area of interest with regard to sustainability as a direct consequence of ongoing concerted international action to combat global warming and its possible consequences. Attention then moved on to establishing an overview of the "start of the art" with respect to BIM, forming a view as to the current capability of BIM to handle sustainability issues in general and those particularly important with regard to refurbishment.

With inclusion regard to inclusion criteria, it should be noted that that by using the search criteria construction, refurbishment, sustainability, assessment, building information modelling and BIM in appropriate combinations yielded a fairly small group of relevant papers when issues around overlap of material and secondary sources had been addressed. In addition, literature related to specific commercial BIM products were excluded. In all, 18 key journal papers and 3 conference papers were identified as being of appropriate originality and relevance. 8 books, 15 report (from a range of sources) and 2 Standards were also identified as being of relevance.

\section{Sustainability issues in construction}

There are more than 30 million buildings in the UK and according to recent estimates, $75 \%$ of the residential building stock that currently exists will still be in use in 2050 (DCLG, 2015). According to the Department for Communities and Local Government, these buildings are major energy consumers and $\mathrm{CO}_{2}$ emitters currently account for about $43 \%$ of overall carbon emissions in the UK. Encouraging energy efficient building refurbishment projects and raising the sustainability standards for new buildings are central elements of the UK governments sustainability strategy. It is upon refurbishment that this paper will focus. 
The achievement of $\mathrm{CO}_{2}$ emission reductions is currently the UK Governments main driver for refurbishment. In order to meet UK national carbon emission targets, approximately 28 million building in the UK will require refurbishment by 2050 . (Edwards and Townsend, 2011). According to Bribián et al., (2011) sustainability enabled refurbishment projects will achieve reductions in carbon emissions and energy consumption through the application of sustainable-led design concepts. This will offer additional opportunities for the achievement of sustainability whilst avoiding consequential environmental impacts, for example, by means of the selection of sustainably sourced building materials for the refurbishment. Successful refurbishment projects will also enhance the condition and appearance buildings and increase its value, in addition to achieving the sustainability objectives, and will also have a positive impact upon the quality of life of occupants.

Sustainability issues rated to construction are not limited to those concerned with energy. Both resource consumption (including materials, water, energy and land) and waste production (throughout all life stages of the project, from design to demolition) are of growing significance. For example, during the construction stage of a building's life a wide variety of different building materials and other resources are used which often lead to the production of large quantities of diverse onsite wastes. This can be exacerbated by lack of planning, unexpected design changes, lack of using sustainable methods, deficiency of sustainable materials and ignorance of the effects that buildings $\mathrm{CO}_{2}$ emissions can have on the environment (Kibert et al., 2011; Olawumi et al., 2018). The UK Green Building Council (GBC, 2013) stated that in 2012 and 2013 the construction and demolition sector was the largest producer of waste in the UK, responsible for producing more than 120 million tonnes of waste every year - around one third of the overall waste in the UK. In addition, at least $10 \%$ of all raw materials delivered to site are wasted through loss, damage and over-ordering. In practice, refurbishment projects can be highly problematic. The unavailability of as-built drawings, plans or blueprints is a major issue and even if they are accessible they may contain inaccuracies (Highfield and Gorse, 2009). Without access to these documents, refurbishment projects are open to a large number of unknowns and risks, causing concerns relating to health and safety and financial uncertainties in addition to potential adverse impacts upon project costs.

\section{Sustainable design in refurbishment projects}

According to Bruntland (1987), the aim of sustainable designs is to develop a building that meets the needs of the present without compromising the ability of future generations to meet their own needs through the evolvement of sustainability led 
decisions during planning, designing, construction and operation of buildings. Historically, the use of the term "sustainable" developed among those with environmental concerns only, and most of the literature reflects this emphasis. However, sustainability is increasingly recognised by many industries such as manufacturing and construction, mainly due to the impact that these industries have on sustainability (Glasser et al., 2005). Sustainable design, also known as 'environmental design' is intended to reduce negative environmental impacts through competent designs (Phillips et al., 2017; McLennan, 2004). It is an integrated holistic approach that encourages compromises and adjustments in order to achieve sustainability within buildings. Such an integrated approach positively impacts all phases of a building's life cycle including design, construction, operation, refurbishment and demolition. The sustainable design concept can be applied across all fields of design whether to design a whole building or just components within a building (Jensen et al., 2018). It can also be applied successfully in the context of refurbishment projects, not only because it can be cost effective in the long term but also designing refurbishment packages with enhanced sustainable attributes can reduce operation costs (for example energy and water consumption) and environmental impacts (for example $\mathrm{CO}_{2}$ emissions) and can result in increased resilience post refurbishment. Sustainable designs, regardless of the application, is targeted to cover the themes shown in Figure 1 in order to achieve environmental outcomes such as:

- Limiting resource consumption through waste-free manufacturing.

- Reducing energy and water consumption through the entire lifecycle.

- Minimising building's impact on climate change.

- Minimising impact on the local environment.

- Reducing or eliminating waste.

- Emphasising quality and durability over price.

- Giving preference to the use of non-toxic materials.

Insert Figure 1

Applying the sustainable design concept on a refurbishment project encourages sustainability-led decisions at each phase of the design process, which can reduce negative impacts on the overall environment and the health of the occupants, without compromising the so called 'bottom line'. Global institutions have established environmental assessment schemes to assist in the adoption of the sustainable design principles as described above. Such schemes use indicators to assess the impacts of a 
project on energy consumption, greenhouse gas emissions, land and water use (Todd et al., 2001). The criteria for assessment typically include management (policy and procedure), operational energy and $\mathrm{CO}_{2}$ emissions, health and well-being, site ecological value, pollution, transport, land use, materials and water consumption efficiency. The popular approach is to award credits (sometimes referred to as marks) under each assessment criterion. Although these schemes differ noticeably in their approaches to applying weightings in the calculation of the importance of different sustainability indicators to produce their final scores, which represents the overall sustainability of the building in question. BREEAM, originating in the UK (Barlow, 2011) and LEED originating in the USA (Kubba, 2017) are both credit-based schemes, with a project gaining credits according to its fulfilment of set criteria; the achieved credits are then scored by a weighting factor that reflects the sustainability priorities within the country in which the project is based. However, both BREEAM and LEED are still far from perfect - but in fairness perfection is probably an unreasonable expectation in the context of sustainability in construction. A number of researchers have indicated that calculations, analyses and interpretations of the results generated by BREEAM and LEED accreditations are ambiguous and sometimes they even include errors. For example, According to Aotake et al., (2005) there are random errors and systematic errors present in both LEED and BREEAM. Furthermore, Haapio and Viitaniemi (2007) stated that systematic errors are more common as they are caused by traditional measuring tools or methods uncertainties and errors may occur in different phases of the environmental assessment of the building, either during calculations or even during the data collection phases. Other researchers have suggested that the interpretation of the results can vary considerably depending on the assessor (Haapio and Viitaniemi, 2007; Trusty and Meil, 2002). Errors in definitions and calculations can have great impacts on the environment, as these definitions are becoming the main source of shaping sustainable decisions in projects. Which leads us to questioning whether the building environmental assessment schemes practically fulfil the sustainable design themes shown in Figure 1 not only for the design phase but also for construction and building operations. According to Kamaruzaman et al. (2016), the technical manuals associated with refurbishment projects for BREEAM and LEED both grade the life cycle energy of materials as the highest points contribution to the overall sustainability criteria with nearly $18 \%$ of the overall BREEAM rating across the Pollution, Materials, Energy and Waste categories, and $14 \%$ of LEED overall rating criteria. The report also indicated that the life cycle energy analysis specified in BREEAM and LEED only refers to the construction materials implemented in a respective building, where other life cycle phases of energy, such as manufacturing, construction, operation and demolition stages are not considered. 
In the BREEAM UK Refurbishment and Fit-out 2014 manual (BRE, 2014), the BRE claims to have considered the inclusion of life cycle energy impacts within their assessment criteria by incorporating the Green Guide specification to analyse the life cycle energy impacts of materials. The Green Guide specification is one of the many tools produced by BRE to offer guidance on the environmental impacts of a building (Anderson et al., 2002). Basnet (2012) states that the criteria defined within the Green Guide specification do not outline how the elements are being rated. The specification only includes whole element ratings rather than the individual materials making up these elements. However, in order to correctly evaluate the overall environmental impacts of a building, all the life cycle stages should be included in order to calculate energy impacts from cradle to grave as specified by PAS2050:2010 and as demonstrated in Figure 2. Adding these criteria correctly to the assessment process will certainly help to encourage better evaluation of the actual environmental impacts of a building.

Insert Figure 2 here

There is a myriad of sustainability assessment schemes globally, for example CASBEE (2018) in Japan, Green Mark (BCA, 2018) in Singapore, Green Star (GBCA, 2018) in Australia and MyCrest (CIDB, 2018) in Malaysia - but all are based on numerous methodologies, using different methods and assessed separately. The assessment themes were further studied and revealed that energy and indoor environmental quality (IEQ) was ranked the highest (Kamaruzzaman et al., 2016). The impact of this paper will indirectly contribute towards all sustainability schemes as energy and IEQ will be discussed in sections below.

\section{Whole-life cycle energy}

The term whole-life cycle energy of materials is important in determining whether building materials are environmentally friendly or not. Generally, building materials consume energy throughout their life cycle starting from the manufacturing stage, passing through the use, and finishing by the deconstruction phase. These stages include raw material extraction, transport, manufacture, assembly, installation as well as disassembly, deconstruction, and decomposition (PAS2050:2010). The whole-life cycle energy of a certain material includes both embodied energy and operating energy. Embodied energy is sequestered in building materials during all processes of production, on-site construction, transportation, final demolition, and 
disposal (Abanda et al., 2017; Nizam et al., 2018). While operational energy is expended in maintaining the inside environment through processes such as heating and cooling, lighting, and operating appliances. Changes to the building regulations have progressively required buildings with lower operational energy and therefore the balance between operational energy use and the embodied energy content implicit in all of the other stages has changed. However, in the UK, limits on embodied energy are still not enshrined within building regulations. Conveniently, embodied energy can be measured in the same units as operational energy and the sum of the two gives a holistic view of the energy implications of design, construction and operation. Sturgis and Roberts (2010) have pointed towards the new form of Environmental Product Declaration (EPD), which provides details of the whole-life cycle energy of materials and products. An EPD is a verified and registered document that communicates transparent and comparable information about the life-cycle environmental impact of a product based on IS014025:2006. For a global perspective, the Swiss Centre for Life Cycle Inventories is probably the leading exponent of EPD, however, the development of the EPD is not as developed in the UK. Although there are a number of other sources for embodied energy data available in the UK, the most frequently used authoritative open-source of data is the ICE database from the University of Bath (Hammond and Jones, 2008). The ICE database contains over 400 values of embodied energy/embodied carbon with 30 main material classifications broken down into approximately 170 different building materials. However, the ICE data is only generated from energy and carbon values of materials on a 'Cradle to Gate' basis (omitting any allowances for transport, waste, operational energy etc.). The ICE database $1^{\text {st }}$ edition in 2010 was based upon $\mathrm{CO} 2$ emissions only, though, in the $2^{\text {nd }}$ edition, the effect of other greenhouse gases is incorporated and the quantity 'CO2 equivalent' ( $\mathrm{CO} 2 \mathrm{e}$ ) is used. Data is also contained within the Green Guide (BRE, 2018). The embodied energy values there are presented as one part of the assessment of elements that are given overall environmental ratings such as $\mathrm{A}+$, A, B etc. The BRE data is described as being from 'Cradle to Grave' over the life of the element, with the implication that all the sources of energy consumption not included in the ICE data are considered. It is understood that much of the source data was provided in confidence and it therefore lacks the transparency of the ICE database. However, the issues with these databases that the basis and rules of measurement of elements are built on assumptions and may change over a period of time such as allowances for transport, waste, life-spans, recycling rates and changes in recycling rates over the lifespan of an element. Many of these assumptions may be realised in practice if PAS 2050:2010 is widely adopted. PAS 2050:2010 is a publicly available standard for assessing the life cycle greenhouse gas emissions of goods and services and is supported by an implementation guide and a code of good practice. Both the UK Building Research Establishment and the US Green Building Council, who are 
responsible for BREEAM and LEED respectively, have both stated that in order to outline and calculate the whole life energy of a building in a reliable manner, the materials within the building will need to be compared like for like, as the ultimate energy performance depends on various factors outside the control of the original design team. Without reliable material data it will be problematic for designers to properly compare the real performance of buildings and will require advanced visual analysis and checking tools to ensure compliance during decision making. The use of BIM tools will still be made more difficult by unreliable materials data, but the enhanced modelling capability makes it easier to study the implications of uncertainties. In addition, technologies exist which enable existing materials to be characterised prior to refurbishment, for example hyperspectral analysis. There are numerous information technology tools that are used for sustainable design in refurbishment projects. Such tools can be used to model designs and analyse the building's energy performance and internal thermal comfort conditions - the integration of whole-life cycle and BIM can provide the sustainability-led design platform for decision makers (Najjar et al., 2017).

\section{BIM for sustainable design}

Design technology using Building Information Modelling (BIM) is maturing for new buildings, but uncommon for refurbishment projects. BIM provides a platform to incorporate existing building plans into a common digital platform for all to share - a revelation for the industry (Charef et al., 2018). This will foster design innovation and creativity, not only for the built environment industry but also through the supply chain and across other sectors. BIM design tools open up potentials for innovation allowing more creative designs and optimised engineering solutions and better ways to satisfy clients and win new work. Using BIM for building design can improve sustainability design decisions and minimise sustainable errors through integrated design tools. However, these tools are currently a long way from achieving their maximum potential.

BIM has been advocated for its potential delivery of more innovative design solutions. The Waste \& Resources Action Programme (WRAP, 2015) stated that using BIM for sustainable design is the essential solution for the sustainability plan as a correspondence to the government's sustainability report in 2012 (NAO, 2012). BIM tools can assist designers to analyse how a building should perform even in the very early stages of the design. This can allow for a coordinated evaluation of design alternatives and make better decisions to enhance sustainable designs (Zakar, 2008). The government's Low Carbon Construction report issued in autumn 2010 stated: "It 
is BIM that is seen as having the greatest potential to transform the habits - and eventually the structure - of the industry" (HM Government, 2010). Consequently in 2011, the UK government made BIM Level 2 mandatory on all public projects by 2016. These statements were built on the potentials that BIM could contribute towards the design, construction and commissioning processes of buildings and consequently to achieve lower environmental impacts. For instance, BIM tools can be used to perform energy simulation during the design process to compare design alternatives using parameters and rules among objects. Nonetheless, designers rarely use BIM energy performance analyses due to the skills required in preparing the energy models and to interpret the outputs. Also, the long time required for energy model simulations is an issue that is diminishing as computer processors are becoming ever more powerful. Within existing buildings, Building Energy Management Systems (BEMS) are commonplace and these potentially are a valuable source of performance data both pre and post refurbishment. In reality, however there is a gulf between the ability to collect data and the will to do anything with it. The current technology in the existing BIM tools does not provide the optimum solution to achieve sustainable designs, although BIM is enriched with additional information and integrated analysis and evaluation tools including daylighting and solar studies, material and product libraries containing construction, maintenance and building management information for each material throughout the entire lifecycle of a building. BIM is not formally integrated and aligned with the existing sustainability frameworks that were developed by the UK government in order to achieve accurate and practical analysis and lead to better informed decision-making at early stages. Although, BIM libraries such as the NBS national BIM library are aiming to make these documents available to designers within BIM design tools for product guidance purposes.

Refurbishment projects are very different from conventional new builds. The application of BIM is common for new buildings, but is still in its infancy for refurbishment projects, including buildings and structures. Data acquisition is the first and most critical issue for refurbishment projects. The ability to acquire, analyse, model and verify as built model is poor for the construction industry (Amano et al., 2018). The ability to confidently acquire accurate data for existing buildings and/or structures for buildings will enable the production of a BIM model, but the industry is far from achieving this (Bassier et al., 2018).

The ability to create a semantic rich and geometrically accurate models can be achieved via point cloud data (PCD) from LiDDAR laser scanners. However, PCDs are 'meaningless points' in a 3-dimension domain. The process of making the point intelligent and meaningful to the computer (in other words, BIM) is still missing (Han 
and Golparvar-Fard, 2015). It is only when PCD of existing structures could be transformed into 2D/3D models, then into BIM models - simulation for sustainabilityled design could materialise. The process of transforming existing data into a verified BIM model is very labour intensive (redraw), riddled with human error and very expensive (Jung et al., 2014). With a BIM model, the process of simulation can be conducted - thermal comfort, lighting, smoke, etc - via an extensive BIM library. The NBS BIM library is an open source of a vast amount of generic and manufacturer 2D and 3D objects authored by experts and authorised by various national standards. These objects consist of detailed information such as technical information and dimensions that defines the product and geometry that represents the product's physical characteristics, the information and dimensions of these objects can be manipulated and updated by the designers once it is uploaded into a BIM model. Using the BIM library during design stages can save time and ensure consistency and current. However, the BIM library contains an extensive number of generic objects that can only be used during concept and schematic design stages with a very small range of specific manufacturer objects that can be used during later design stages. Currently, there are different BIM tools that provide designers with an opportunity to explore different energy saving alternatives at early design stages in order to make energy related decisions that have a high impact on the proposed building life cycle cost (Krygiel and Nies, 2008). There are several BIM sustainable design tools available to assist in insuring that sustainability standards are achieved. These depend, fundamentally, upon a virtual building for the analysis. However, since these issues are associated with sustainability, BIM sustainability design tools are assessed in this research to ensure that the project complies with relevant environmental assessment schemes such as BREEAM and LEED.

\section{BIM sustainability decision-support tools}

Traditionally, specialist consultants carry out environmental analysis of a design only after the design is complete. However, BIM tools aim to enable the construction of a digital virtual 3D building model at early design stages, which can provide designers the ability to explore and analyse different options for sustainable designs. BIM analysis tools provide building thermal simulation, including dynamic analysis of energy performance calculating thermal loads and thermal consumption of a building. With further features such as local weather data and provision of local building materials, construction and codes, the number of tools users is growing enormously. Currently, there are more than 400 applications that can be applied to

analyse building energy and thermal simulation. These tools are diverse, ranging from research software used and accessed by limited users to commercial products 
with thousands of users. Most of these tools are restricted by limited hardware platforms. Therefore, it can make the simulators restricted with certain formats for exporting and importing the models. Figure 3 demonstrates some of the large venders have flexibility for data exchange between modelling tools and thermal simulation tools conducted in various formats, primarily by IFC and gbXML. These tools vary in their thermodynamic model capabilities, graphical user interfaces, purpose of use, life-cycle applicability and ability to exchange data with other software applications. Some tools incorporate local weather data and provision of local building materials, construction and codes. Despite the benefits that these analysis tools can provide, there are various technology, process and social disadvantages. The first of these disadvantages is that simulation input data and results must be subjected to careful use to avoid errors in simulation. For example, typographical errors during data input can produce spurious results and locating the input data errors can be a very laborious task. It should never be forgotten that no matter how advanced simulation tools are, they can only produce predictions as opposed to absolute truths. The simulation predictions cannot and should not be blindly relied on as the different elements and materials in the model can in reality be affected by unforeseen issues. Indeed, in some cases, the simulation results can be difficult to interpret except by an experienced simulation tool user. In addition, embracing these tools is not a straightforward process. Although most of the tools are free to download, they require special training in their use and access to computer hardware of sufficient power.

\section{Insert Figure 3 here}

One area of challenge is the development of standard sustainability tools to guide professionals in making conceptual design decisions among alternative solutions. Although a number of sustainability assessment tools exist, it has been challenging for designers to apply them to amend designs according to sustainable alternatives. Reviewing and comparing the mostly used tools will allow identification of the data exchange according to the design phases that each tool can be implied and the BREEAM and LEED criteria through the BIM platform. There are no BIM sustainability tools specifically for refurbishment projects so far. The design team will have to recreate a digital twin of the existing building or structure, and conduct analysis as for a new built. In cooperating BREEAM/LEED criteria into modelling software in a 'live' scenario will provide designers with insights of different materials to be used for different scenarios of the building design. This will provide a more informed decision-making process throughout the lifecycle and facilities management phase of the refurbishment process. 


\section{Discussion}

The construction sector has a have a major impact on the environment - during the construction of new buildings or the refurbishment of existing buildings, affecting the global climate by using a considerable number of resources, materials and energy and contributing to a large amount of carbon and energy emissions. Buildings should be designed and materials selected to balance the whole life cycle of energy with factors such as climate, availability of materials and transport costs. Lightweight building materials often have lower embodied energy than heavyweight materials, but in some situations, lightweight construction may result in higher energy use. For example, where heating or cooling requirements are high, this may raise the overall energy use of the building. As described above, the whole life cycle energy comprises of the embodied energy and operating energy. The embodied energy can be manually calculated on a 'Cradle-to-Gate' basis for each material. However, In the UK there is a number of sources for calculated embodied energy data, ICE database is known as the main reliable and open-source of data, structured into 34 main material groups with over 1700 records on embodied energy (carbon). Although, rather than calculating embodied energy, manufactures should be obliged to provide reviewed embodied energy calculations of their products so that data can be integrated within BIM and used to inform all stages of design. On the other hand, the operating energy of materials can be obtained via simulation once the embodied energy is in place with the involvement of heating, cooling, lighting, and operating appliances integrated within BIM design tools. However, it is also recommended to use the whole life cycle energy of materials produced by the Environmental Product Declaration (EPD).

The issues of sustainable refurbishment have been intensively tackled for years in many developed countries. As the current process of sustainable design iterations in refurbishment projects is progressing from traditional CAD systems towards the adoption of BIM, different strategies of integral refurbishment were developed and generated a number of effective environmental assessment methods and tools. These different environmental assessment tools were tested for this research, which showed that each tool is used to mitigate sustainable effects and to improve the building construction process to overtake some obstacles for sustainable refurbishment. However, the following points were identified. Firstly, None of the BIM sustainability decision-support tools can be used during the design development

phase; therefore, BIM cannot be used as a decision support optimisation tool during the early designing phases of refurbishment projects. Secondly, despite the efforts of mitigating and optimising energy by the different BIM sustainability tools, the energy 
usage in construction and production of materials (whole-life cycle energy) is still not achieved by any of the tools examined in Table 1.

\section{Insert Table 1}

The concept of sustainability-led design will require the industry to have a mindset shift from the traditional short-term iron triangle ideology of time-cost-quality, and to move towards foresighting and sustainability focused ideology. The mindset of longer-term benefits from the use and selection of materials, energy preservation designs and minimum (not zero) emissions buildings will be needed to undertake this new concept.

\section{Conclusions}

This paper concludes that while BIM is widely recognised as a suitable digitised representation of the physical building, it is not yet all encompassing and as such it is a long way from having its full potential realised. Much of the current usage of BIM only focuses on the traditional project management triumvirate of time-cost-quality and generally neglects aspects of sustainability-design-process. The inclusion and accessibility of essential sustainability information such as the life cycle energy of materials can provide designers and decision makers with a great insight of how sustainable each material is within their design to allow for accurate comparison between different sustainable designs. Therefore, it is essential to develop a decision support tool that can evaluate the life cycle energy of materials within BIM in order to encourage the inclusion of whole life energy of materials by the environmental assessment schemes and assist the design team in making knowledgeable sustainability decisions and recommendations. It is acknowledged that the recreation of a digital twin of the refurbishment project will consume much time, cost and labour - hence, the focus now should be on the automated scan-to-BIM process.

BIM models should contain an integrated library of whole life cycle energy information for each material and ideally this library would be standardised between models. This would make the energy lifecycle comparison of different materials easier than manual calculations. Also, when substituting materials or products at later work stages, the impacts of doing so will be transparent to all parties and the total life cycle energy of a building will automatically change with each iteration. The integration of reliable, up-to-date, research-based information of embodied energy within BIM library is crucial and is highly recommended, taken in consideration the current criteria of sustainability for refurbishment projects. 


\section{Acknowledgements}

This work was supported by Newton-Ungku Omar Fund Institutional Links with Malaysia supported by British Council and the Malaysian Industry Government Group for High Technology (MIGHT) (Grant ID 172726659). 


\section{References}

1. Abanda, F.H., Oti, A.H. and Tah, J.H.M. (2017), "Integrating BIM and new rules of measurement for embodied energy and CO2 assessment", Journal of Building Engineering, 12, 288-305.

2. Amano, K., Lou, E.C.W. and Edwards, R. (2018), "Integration of point cloud data and hyperspectral imaging as a data gathering methodology for refurbishment projects using building information modelling (BIM)", Journal of Facilities Management, in press. (https://doi.org/10.1108/JFM-11-2017-0064)

3. Anderson, J., Shiers, D. E. and Sinclair, M. (2002), The Green Guide to Specification: An Environmental Profiling System for Building Materials and Components, Wiley-Blackwell, London, UK.

4. Aotake, N., Ofuiji, N., Miura, M., Shimada, N. and Niwa, H. (2005), "Comparison among results of various comprehensive assessment systems - a case study for a model building using CASBEE, BREAAM and LEED", Proceedings of the 2005 Sustainable Building Conference (SBO5), Tokyo, Japan.

5. Barlow, S. (2011), A guide to BREEAM, RIBA Publishing, London, UK.

6. Basnet, A. (2012), BREEAM \& LEED: A study of materials and their life cycle impacts. Use and Operation of Zero Emission Buildings, Norwegian University of Science and Technology (NTNU), Norway.

7. Bassier, M., Genechten, B.V. and Vergauwen, M. (2018), "Classification of sensor independent point cloud data of building objects using random forests", Journal of Building Engineering, in press (https://doi.org/10.1016/j.jobe.2018.04.027)

8. BCA (2018), BCA Green Mark Scheme, Building and Construction Authority, https://www.bca.gov.sg/greenmark/green mark buildings.html [Date assessed 1 October 2018].

9. BRE (2014), BREEAM UK Refurbishment and Fit-out 2014 manual, Building Research Establishment (BRE). http://www.breeam.com/ndrefurb2014manual/ [Accessed 05 August 2017].

10. BRE (2018), Green Guide to Specification, Building Research Establishment (BRE) https://www.bre.co.uk/greenguide/podpage.jsp?id=2126 [Last accessed 4 January 2018].

11. Bribián. I.Z, Capilla, A.Va and Usón. A.A. (2011), "Life cycle assessment of building materials: comparative analysis of energy and environmental impacts and evaluation of the eco-efficiency improvement potential", Building and Environment, 46(5), 1133-1140.

12. Bruntland, G. (1987), The Bruntland Report, HMSO, London, UK.

13. CASBEE (2018), Comprehensive Assessment System for Built Environment Efficiency, http://www.ibec.or.jp/CASBEE/english/ [Date assessed 1 October 2018].

14. Cavalliere, C., Dell'Osso, G.R., Pierucci, Alannone, ., F. Life cycle assessment data structure for building information modelling, J. Clean. Prod. 199 (2018) 193-204. oi:10.1016/j.jclepro.2018.07.149.. 
15. Charef, R., Alaka, H. and Emmitt, S. (2018), "Beyond the third dimension of BIM: A systematic review of literature and assessment of professional views", Journal of Building Engineering, 19, 242-257.

16. CIDB (2018), MyCrest, Construction Industry Development Board Malaysia http://www.cidb.gov.my/index.php/en/bidang-utama/pembinaanmampan/mycrest [Date assessed 1 October 2018].

17. DCLG (2015), Policy Paper: Energy Efficiency in Buildings, Department for Communities and Local Government, HMSO, London, UK.

18. Edwards, J. and Townsend, A. (2010), "We're Cool: Carbon Reduction and Built Heritage Can Coexist", Construction Research and Innovation (CRI), 1(4), 36-37.

19. GBC (2013), UK-GBC Impact Report (2012-2013), UK Green Building Council. http://www.ukgbc.org/sites/default/files/Impact\%2520Report\%2520WEB 1.pdf [Accessed 8 November 2015].

20. GBCA (2018), Green Star, Green Building Council Australia, https://new.gbca.org.au/green-star/ [Date assessed 1 October 2018].

21. Glasser, H., Calder, W. and Fadeeva, Z. (2005), Definition: Research in Higher Education for Sustainability, Halifax Consultation, Halifax Nova Scotia, Scotland.

22. Haapio, A. and Viitaniemi, P. (2007), "Environmental criteria and indicators used in environmental assessment of buildings", Proceedings of the CIB World Building Congress 2007: Construction for Development, Cape Town, South Africa, 24062416.

23. Hammond, G.P. and Jones, C.I. (2008), "Embodied energy and carbon in construction materials", in the Proceedings of the Institution of Civil Engineers, 161, 87-98.

24. Han, K.K. and Golparvar-Fard, M. (2015), "Appearance-based material classification for monitoring of operation-level construction progress using 4D BIM and site photologs", Automation in Construction, 53, 44-57.

25. Highfield, D. and Gorse, C. (2009), Refurbishment and Upgrading of Buildings, Taylor \& Francis, London, UK.

26. HM Government (2010), Low Carbon Construction Innovation \& Growth, BIS/11/10/NP, London, UK.

27. ISO 14025:2006, Environmental Labeling and Declarations - Type III Environmental Declarations Principals and Procedures. International Standards Organisation, Geneva, Switzerland.

28. Jensen, P.A., Maslesa, E., Berg, J.B. and Thuesen, C. (2018), "10 questions concerning sustainable building renovation", Building and Environment, 143, 130-137.

29. Jung, J., Hong, S., Jeong, S., Kim, S., Cho, H., Hong, S. and Heo, J. (2014), "Productive modeling for development of as-built BIM of existing indoor structures", Automation in Construction, 42, 68-77.

30. Kamaruzaman, S.N., Lou, E.C.W., Zainon, N., Zaid, N.S.M. and Wong, P.F. (2016), "Environmental Assessment Schemes for Non-Domestic Building Refurbishment in the Malaysian Context", Ecological Indicators, 69, 548-558. 
31. Kibert, C. J., Thiele, L., Peterson, A. and Monroe, M. (2011), The Ethics of Sustainability. http://rio20.net/wp-content/uploads/2012/01/Ethics-ofSustainability-Textbook.pdf [Accessed 21 September 2018].

32. Krygiel, E. and Nies, B. (2008), Green BIM: successful sustainable design with building information modelling, John Wiley and Sons, UK.

33. Kubba, S. (2017), Handbook of Green Building Design and Construction - LEED, BREEAM, and Green Globes, $2^{\text {nd }}$ Edition, Butterworth Heinemann, MA, USA.

34. McLennan, J. F. (2004), The philosophy of sustainable design: The future of architecture, Ecotone publishing, UK.

35. Meex, E., Hollberg, A., Knapen, E., Hildebrand, L. and Verbeeck, GF. (2018), "Requirements for applying LCA-based environmental impact assessment tools in the early stages of building design", Building and Environment, 133, 228-236

36. Najjar, M., Figueiredo, K., Palumbo, M. and Haddad, A. (2017), "Integration of BIM and LCA: Evaluating the environmental impacts of building materials at an early stage of designing a typical office building", Journal of Building Engineering, $14,115-126$.

37. NAO (2012), NAO annual report - sustainability, National Audit Office (NAO) Available at https://www.nao.org.uk/wpcontent/uploads/2012/05/NAO AR 2012.pdf [Last accessed 5 October 2015].

38. Nizam, R.S., Zhang, C. and Tian, L. (2018) "A BIM based tool for assessing embodied energy for buildings", Energy and Buildings, 170, 1-14.

39. Olawumi, T.O., Chan, D.W.M., Wong, J.K.W. and Chan, A.P.C. (2018), "Barriers to the integration of BIM and sustainability practices in construction projects: $A$ Delphi survey of international experts", Journal of Building Engineering, 20, 6071.

40. PAS2050 (2010), Specification for the assessment of the life cycle greenhouse gas emissions of goods and services, British Standards Institution (BSI), London, UK.

41. Phillips, R., Troup, L., Fannon, D. and Eckelman, M.J. (2017), "Do resilient and sustainable design strategies conflict in commercial buildings? A critical analysis of existing resilient building frameworks and their sustainability implications", Energy and Buildings, 146, 295-311.

42. Sacks, R., Eastman, C., Lee, G. and Teicholz, P. (2018), BIM Handbook: A Guide to Building Information Modeling for Owners, Designers, Engineers, Contractors, and Facility Managers, Third Edition.

43. Sturgis, S. and Roberts, G. (2010), Redefining zero: Carbon profiling as a solution to whole life carbon emission measurement in buildings, RICS Research, London, UK.

44. Todd, J., Crawley, D., Geissler, S. and Lindsey, G. (2001), "Comparative assessment of environmental performance tools and the role of the green building challenge", Building Research \& Information, 29(5), 324-335.

45. Trusty, W. B. and Meil, J. K. (2002), "Building life cycle assessment: residential case study", Proceedings of Mainstreaming Green: Sustainable Design for Buildings and Communities, Chattanooga, TN, 10-20. 
46. WRAP (2015), Waste \& Resources Action Programme Annual, Waste and Resources Action Programme (WRAP).

http://www.wrap.org.uk/sites/files/wrap/WRAP\%20Annual\%20Report\%20and\% 20Consolidated\%20Accounts\%202015.pdf [Last accessed 5 October 2015].

47. Zakar, S. (2008), Wastage Rate Report, Building Research Establishment (BRE), Garston, UK. 


\begin{tabular}{|c|c|c|c|c|c|}
\hline BIM Tool & $\begin{array}{c}\text { Design } \\
\text { development } \\
\text { phase }\end{array}$ & $\begin{array}{c}\text { Design } \\
\text { completion } \\
\text { phase }\end{array}$ & $\begin{array}{l}\text { BREEAM } \\
\text { categories }\end{array}$ & $\begin{array}{c}\text { LEED } \\
\text { categories }\end{array}$ & $\begin{array}{l}\text { Modeling } \\
\text { approach }\end{array}$ \\
\hline $\begin{array}{l}\text { Integrated } \\
\text { Environmental } \\
\text { Solutions (IES) } \\
\text { Family }\end{array}$ & & $\checkmark$ & $\begin{array}{ll}- & \text { Hea } 01 \\
- & \text { Hea } 02 \\
\text { - } & \text { Hea } 04 \\
\text { - } & \text { Ene } 03\end{array}$ & $\begin{array}{l}\text { - Energy \& } \\
\text { atmosphere } \\
\text { - Indoor } \\
\text { Environmental } \\
\text { Quality }\end{array}$ & $\begin{array}{l}\text { Performance } \\
\text { Analysis, } \\
\text { Credit } \\
\text { Assessment }\end{array}$ \\
\hline $\begin{array}{l}\text { Simplified } \\
\text { Building } \\
\text { Energy } \\
\text { (SBEM) } \\
\text { Family }\end{array}$ & & $\checkmark$ & $\begin{array}{ll}\text { - } & \text { Hea } 01 \\
\text { - } & \text { Hea } 02 \\
\text { - } & \text { Hea } 03 \\
\text { - } & \text { Hea } 04 \\
\text { - } & \text { Ene } 03 \\
\text { - } & \text { Wst } 05\end{array}$ & & $\begin{array}{l}\text { Energy } \\
\text { Assessment }\end{array}$ \\
\hline $\begin{array}{l}\text { Green } \\
\text { Building } \\
\text { Studio by } \\
\text { Autodesk }\end{array}$ & & $\checkmark$ & $\begin{array}{ll}- & \text { Hea } 01 \\
\text { - } & \text { Hea } 02 \\
\text { - } & \text { Hea } 04\end{array}$ & $\begin{array}{l}\text { - Energy \& } \\
\text { atmosphere } \\
\text { - Indoor } \\
\text { Environmental } \\
\text { Quality }\end{array}$ & $\begin{array}{l}\text { Energy } \\
\text { Analysis }\end{array}$ \\
\hline $\begin{array}{r}\text { DesignBuild } \\
\text { er by Autodesk }\end{array}$ & & $\checkmark$ & $\begin{array}{ll}- & \text { Hea } 01 \\
- & \text { Hea } 02 \\
\text { - } & \text { Hea } 04 \\
\text { - } & \text { Ene } 03\end{array}$ & $\begin{array}{l}\text { - Energy \& } \\
\text { atmosphere } \\
\text { - Indoor } \\
\text { Environmental } \\
\text { Quality }\end{array}$ & $\begin{array}{l}\text { Energy } \\
\text { Assessment, } \\
\text { modeling and } \\
\text { simulation }\end{array}$ \\
\hline $\begin{array}{l}\text { AECOsim } \\
\text { Energy } \\
\text { Simulator by } \\
\text { Bentley }\end{array}$ & & $\checkmark$ & $\begin{array}{ll}- & \text { Hea } 01 \\
\text { - } & \text { Hea } 02 \\
\text { - } & \text { Hea } 04 \\
\text { - } & \text { Ene } 03\end{array}$ & $\begin{array}{l}\text { - Energy \& } \\
\text { atmosphere } \\
\text { - Indoor } \\
\text { Environmental } \\
\text { Quality }\end{array}$ & $\begin{array}{l}\text { Calculation } \\
\text { and } \\
\text { simulation of } \\
\text { inner and } \\
\text { outer } \\
\text { temperatures }\end{array}$ \\
\hline $\begin{array}{l}\text { EcoDesigner } \\
\text { Star by } \\
\text { ArchiCAD }\end{array}$ & & $\checkmark$ & $\begin{array}{ll}- & \text { Ene } 03 \\
- & \text { Mat } 05\end{array}$ & $\begin{array}{l}\text { - Energy \& } \\
\text { atmosphere }\end{array}$ & $\begin{array}{l}\text { Energy } \\
\text { modeling and } \\
\text { analysis }\end{array}$ \\
\hline $\begin{array}{l}\text { ECOTECT by } \\
\text { Autodesk }\end{array}$ & & $\checkmark$ & $\begin{array}{ll}\text { - } & \text { Hea } 01 \\
\text { - } & \text { Hea } 02 \\
\text { - } & \text { Hea } 03 \\
\text { - } & \text { Hea } 04 \\
\text { - } & \text { Ene } 03 \\
\text { - } & \text { Mat } 03 \\
\text { - } & \text { Mat } 05 \\
\text { - } & \text { Pol } 04\end{array}$ & $\begin{array}{l}\text { - Sustainable } \\
\text { Sites } \\
\text { - Energy \& } \\
\text { atmosphere } \\
\text { - Indoor } \\
\text { Environmental } \\
\text { Quality }\end{array}$ & $\begin{array}{l}\text { Building } \\
\text { performance } \\
\text { analysis and } \\
\text { visualisation }\end{array}$ \\
\hline
\end{tabular}

Table 1 - BIM Sustainability decision-support tools in compliance with BREEAM and LEED 


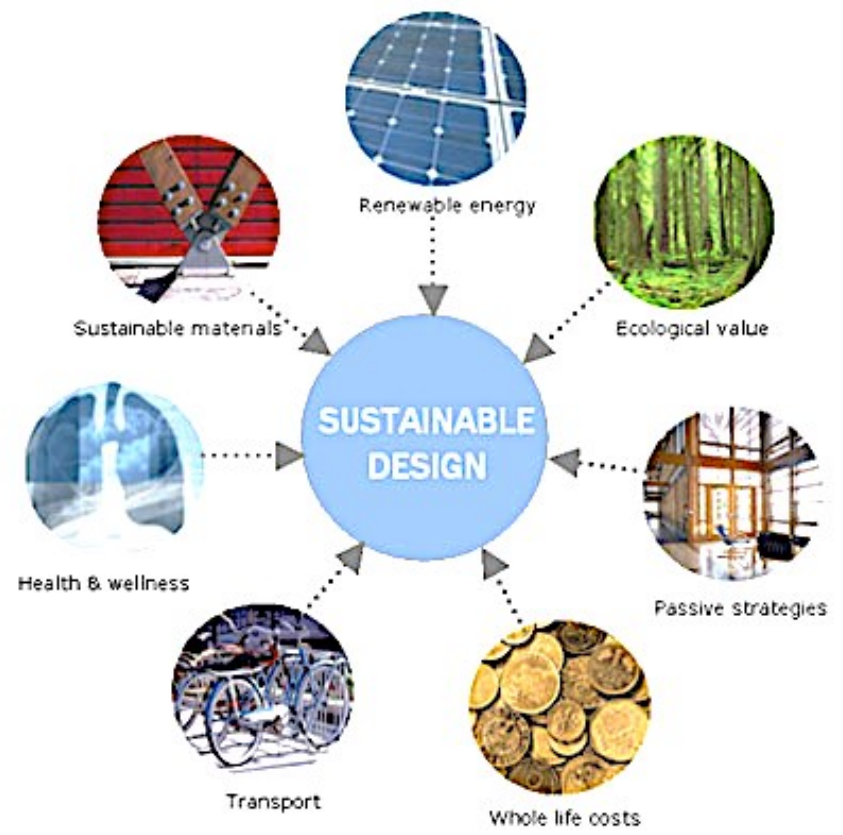

Figure 1: Sustainable design themes (RIBA, 2015)

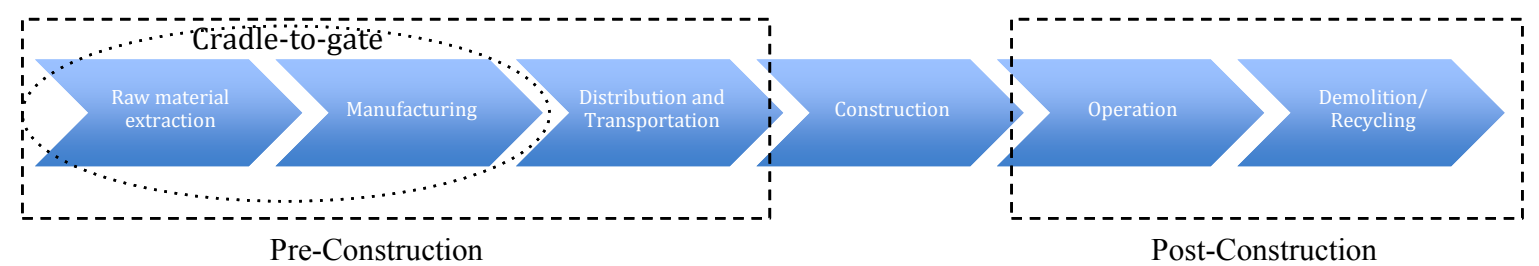

Figure 2: Cradle-to-gate assessment for construction materials (adopted from PAS2050:2010) 


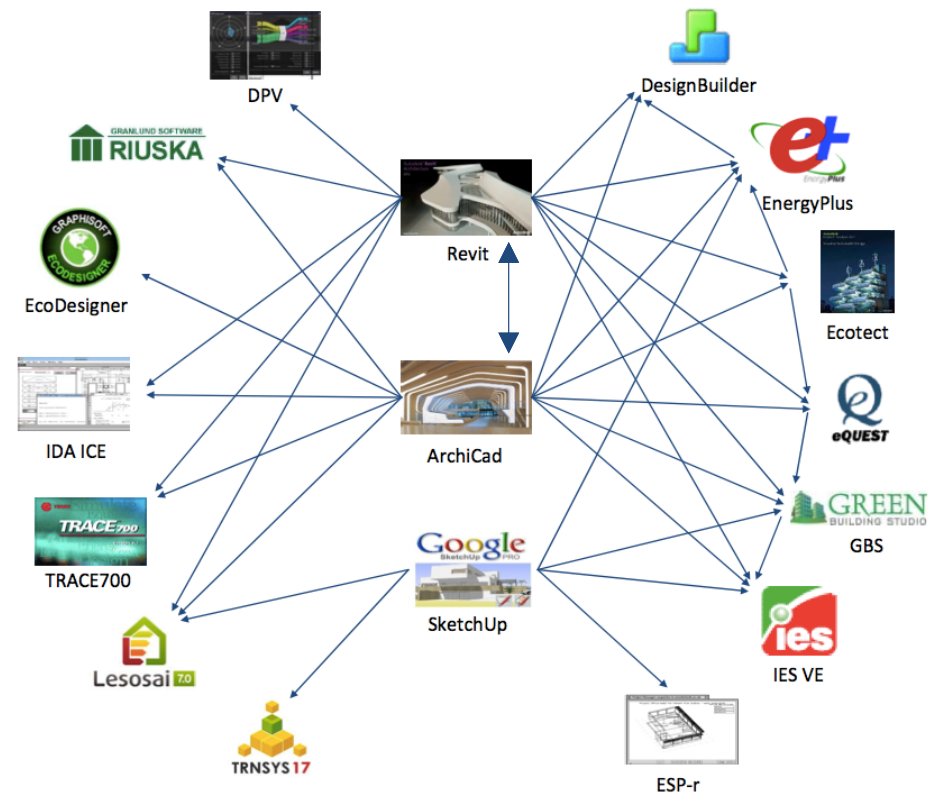

Figure 3: Data exchange between modelling tools and thermal simulation tools 